\title{
Conditional Spike Backpropagation Generates Burst Discharge in a Sensory Neuron
}

\author{
N. LEMON AND R. W. TURNER \\ Department of Cell Biology and Anatomy, Neuroscience Research Group, University of Calgary, Calgary, Alberta T2N 4N1, \\ Canada
}

Received 17 February 2000; accepted in final form 16 May 2000

Lemon, N. and R. W. Turner. Conditional spike backpropagation generates burst discharge in a sensory neuron. J Neurophysiol 84: 1519-1530, 2000. Backpropagating dendritic $\mathrm{Na}^{+}$spikes generate a depolarizing afterpotential (DAP) at the soma of pyramidal cells in the electrosensory lateral line lobe (ELL) of weakly electric fish. Repetitive spike discharge is associated with a progressive depolarizing shift in somatic spike afterpotentials that eventually triggers a highfrequency spike doublet and subsequent burst afterhyperpolarization (bAHP). The rhythmic generation of a spike doublet and bAHP groups spike discharge into an oscillatory burst pattern. This study examined the soma-dendritic mechanisms controlling the depolarizing shift in somatic spike afterpotentials, and the mechanism by which spike doublets terminate spike discharge. Intracellular recordings were obtained from ELL pyramidal somata and apical dendrites in an in vitro slice preparation. The pattern of spike discharge was equivalent in somatic and dendritic regions, reflecting the backpropagation of spikes from soma to dendrites. There was a clear frequencydependent threshold in the transition from tonic to burst discharge, with bursts initiated when interspike intervals fell between $\sim 3-7 \mathrm{~ms}$. Removal of all backpropagating spikes by dendritic TTX ejection revealed that the isolated somatic AHPs were entirely stable at the interspike intervals that generated burst discharge. As such, the depolarizing membrane potential shift during repetitive discharge could be attributed to a potentiation of DAP amplitude. Potentiation of the DAP was due to a frequency-dependent broadening and temporal summation of backpropagating dendritic $\mathrm{Na}^{+}$spikes. Spike doublets were generated with an interspike interval close to, but not within, the somatic spike refractory period. In contrast, the interspike interval of spike doublets always fell within the longer dendritic refractory period, preventing backpropagation of the second spike of the doublet. The dendritic depolarization was thus abruptly removed from one spike to the next, allowing the burst to terminate when the bAHP hyperpolarized the membrane. The transition from tonic to burst discharge was dependent on the number and frequency of spikes invoking dendritic spike summation, indicating that burst threshold depends on the immediate history of cell discharge. Spike frequency thus represents an important condition that determines the success of dendritic spike invasion, establishing an intrinsic mechanism by which backpropagating spikes can be used to generate a rhythmic burst output.

\section{IN T R O D U C T I O N}

Burst discharge in sensory circuits can play an important role in encoding stimulus features or synchronizing activity

\footnotetext{
Address for reprint requests: R. W. Turner, Neuroscience Research Group, University of Calgary, 3330 Hospital Dr. N.W., Calgary, Alberta T2N 4N1, Canada (E-mail: rwturner@ucalgary.ca).
}

across widely disparate regions (Lisman 1997; Ritz and Sejnowski 1997). Oscillatory burst discharge consists of the rhythmic generation of spikes grouped in a burst and a subsequent hyperpolarization of membrane potential. The depolarizing phase of a burst is often driven by a depolarizing afterpotential (DAP) which can be generated by any of several inward currents (Azouz et al. 1996; Bourque 1986; Ghamari-Langroudi and Bourque 1998; Higashi et al. 1993; Hoehn et al. 1993; Huguenard 1996). We have shown that a DAP can also be generated at the soma by backpropagating dendritic $\mathrm{Na}^{+}$ spikes in electrosensory lateral line lobe (ELL) pyramidal cells (Lemon and Turner 1999; Turner et al. 1994). These are principal output cells in an electrosensory system which enables these animals to electrolocate with respect to external electric fields (Bullock and Heiligenberg 1986; Heiligenberg 1991; Moller 1995; Turner et al. 1999). Sodium spikes are initiated near the soma and exhibit a substantial increase in duration as they backpropagate $\sim 200 \mu \mathrm{m}$ into apical dendrites (Turner et al. 1994). As a result, current flow associated with dendritic spike discharge sources back to the soma to generate a DAP that follows the somatic spike. During repetitive discharge the peak amplitude of the DAP increases, resulting in a depolarizing membrane potential shift that eventually reaches threshold for a high-frequency spike doublet. The spike doublet is followed by a burst afterhyperpolarization (bAHP) that temporarily prevents spike discharge. The process underlying the depolarizing shift and generation of a spike doublet can thus group cell output into a series of oscillatory spike bursts.

The ability for backpropagating dendritic spikes to directly influence somatic membrane potential has become apparent in physiological and modeling studies (Golding et al. 1999; Larkum et al. 1999; Magee and Carruth 1999; Mainen and Sejnowski 1996; Turner et al. 1994; Wang 1999; Yuste et al. 1994; Zhang et al. 1993). Spike doublets have also been reported in several bursting cell types, although their role in burst discharge has not been determined (Calvin and Sypert 1976; Ermentrout and Kopell 1998; Koch 1999; Lo et al. 1998; Paré et al. 1995; Whittington et al. 1997). As found for many sensory neurons, spike bursts in ELL pyramidal cells have a demonstrated role in feature detection in vivo (Gabbiani et al. 1996; Lisman 1997). Furthermore, pyramidal cells exhibit a frequency selectivity across multiple topographic maps in vivo

\footnotetext{
The costs of publication of this article were defrayed in part by the payment of page charges. The article must therefore be hereby marked "advertisement" in accordance with 18 U.S.C. Section 1734 solely to indicate this fact.
} 
that correlates with the properties of spike bursts across these maps in vitro (Shumway 1989; Turner et al. 1996). Thus the ELL represents an ideal system to investigate the underlying basis and significance of burst discharge in sensory neurons.

This study examines the soma-dendritic mechanisms underlying the somatic depolarizing shift and spike doublet generation during oscillatory discharge in ELL pyramidal cells. We describe a novel mechanism by which spike frequency establishes a conditional form of backpropagation that generates an oscillatory pattern of spike bursts.

\section{MET HODS}

Weakly electric Apteronotus leptorhynchus were obtained from local importers and maintained at $26-28^{\circ} \mathrm{C}$ in fresh water aquaria. All chemicals were obtained from SIGMA (St. Louis, MO) unless otherwise noted. In all cases, recordings were obtained from separate pyramidal cell somata or apical dendrites using an in vitro slice preparation. Animals were anesthetized in a small tank containing $0.05 \%$ phenoxy-ethanol, and ELL tissue slices of 300-450 $\mu \mathrm{m}$ thickness prepared as described previously (Kotecha et al. 1997; Turner et al. 1994). Slices were cut by Vibratome along either the transverse or longitudinal axis into a bicarbonate-buffered artificial cerebrospinal fluid (ACSF) consisting of (in $\mathrm{mM}$ ): $124 \mathrm{NaCl}, 2.0 \mathrm{KCl}, 1.25$ $\mathrm{KH}_{2} \mathrm{PO}_{4}, 1.5 \mathrm{CaCl}_{2}, 1.5 \mathrm{MgSO}_{4}, 24 \mathrm{NaHCO}_{3}$, and 10 D-glucose $(\mathrm{pH}$ 7.4). In some cases, slices were cut in a reduced chamber filled with a sucrose-based ACSF consisting of (in $\mathrm{mM}$ ): 218 sucrose, 25 $\mathrm{NaHCO}_{3}, 3.25 \mathrm{~K}$ Gluconate, $4.5 \mathrm{MgCl}_{2}, 0.1 \mathrm{CaCl}_{2}, 10$ Glucose, and $1 \mathrm{Na}$ pyruvate (Kotecha et al. 1997) and transferred to a Petri dish containing regular ACSF. In the latter slices more cells appeared to be available for recording but there were no significant differences in the physiological properties of pyramidal cells in slices cut in either medium. Slices were maintained as an interface preparation at room temperature in an oxygenated $\left(95 \% \mathrm{O}_{2}-5 \% \mathrm{CO}_{2}\right)$ in vitro slice chamber.

The majority of pyramidal cell recordings were obtained in the centromedial segment (CMS) map of the ELL. Since identification of segmental maps can be difficult in slices cut with a longitudinal orientation, a limited number of recordings may also have been obtained from the centrolateral (CLS) or lateral (LS) segmental maps. Glass microelectrodes were backfilled with $2 \mathrm{~m} \mathrm{~K}$ acetate ( $\mathrm{pH} 7.4$; $\sim 90 \mathrm{~m} \Omega$ resistance) and intracellular recordings were obtained from either pyramidal cell somata or apical dendrites. Unless otherwise indicated, all dendritic recordings were obtained $\sim 150 \mu \mathrm{m}$ from the cell body layer near the border between the tractus stratum fibrosum and the molecular layer (Maler 1979). Input resistance in somatic recordings ranged between 23 and $122 \mathrm{M} \Omega[73 \pm 21.0(\mathrm{SD}) \mathrm{M} \Omega]$ and in dendritic recordings between 31 and $90 \mathrm{M} \Omega(74 \pm 12.7 \mathrm{M} \Omega ; n=$ 10 random samples). The similarity of these values reflects the fact that dendritic recordings obtained $200 \mu \mathrm{m}$ from the soma are within 0.36 electrotonic length according to recent modeling studies (B. Doiron, L. Maler, and A. Longtin, unpublished data). Resting potential at the soma was $-77 \pm 10 \mathrm{mV}$ and in dendrites $-76 \pm 7.8 \mathrm{mV}$
A Dendrite

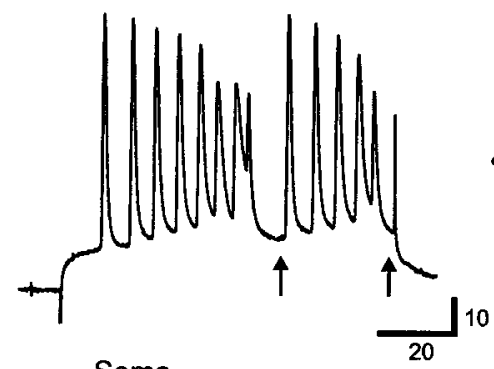

Soma

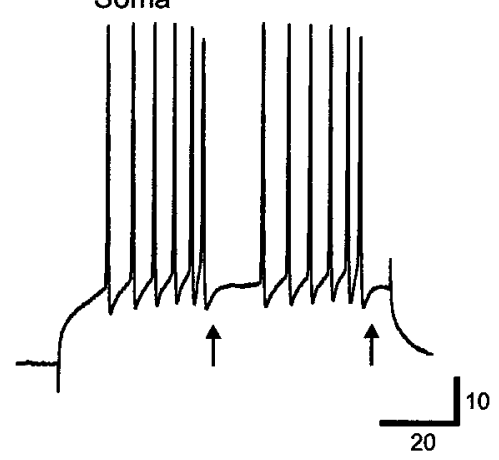

B

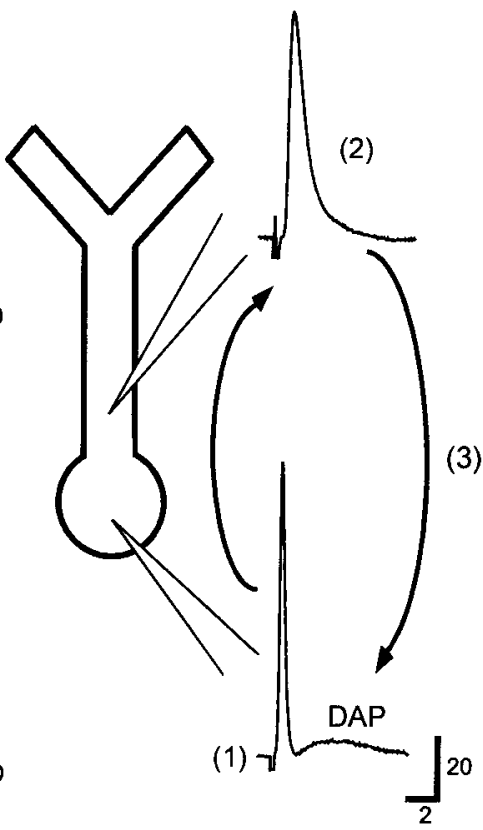

C Dendrite

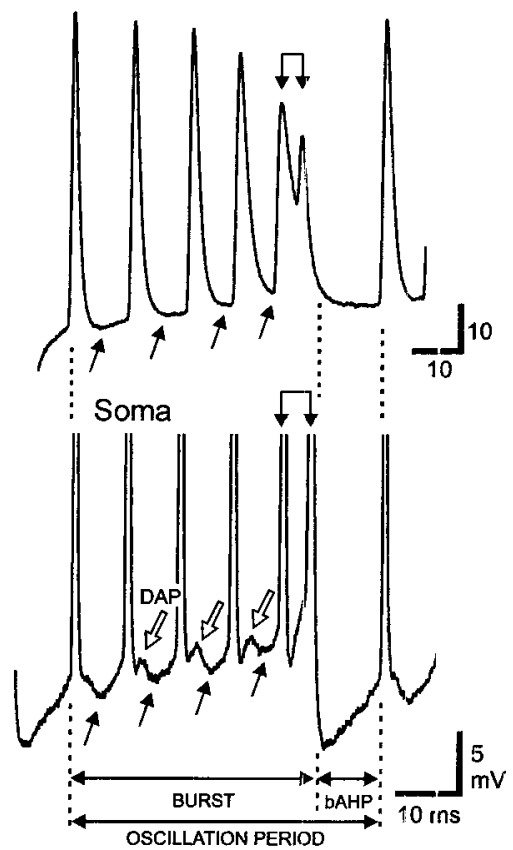

FIG. 1. A: representative examples of oscillatory spike bursts evoked by DC injection. Recordings were obtained from separate pyramidal cell somatic and apical dendritic recordings in this and all subsequent figures. Oscillatory discharge in each location is comprised of a series of spikes grouped into bursts by the rhythmic generation of a spike doublet and bAHP (arrows). $B$ : mechanism for generating a somatic DAP. A schematic diagram of a pyramidal cell is shown next to representative recordings of antidromically evoked spikes in separate somatic and dendritic recordings (150-200 $\mu \mathrm{m})$. The process of generating a DAP begins when a spike is initiated at the soma (1) and backpropagates over the proximal dendritic arbor (2) to generate a long duration dendritic spike. The prolonged dendritic spike simultaneously results in return current flow to the soma which generates a DAP (3). C: expanded views of representative single spike bursts from separate dendritic and somatic recordings (somatic spikes truncated), with bursts approximately aligned to facilitate comparisons. At the soma there is a pronounced reduction in AHPs (solid arrows) and an increase in DAP amplitude (open arrows) during repetitive discharge. A comparatively small sAHP in dendrites (small arrows) is reduced to produce an underlying membrane depolarization. Bursts are terminated on the generation of a high-frequency spike doublet (double linked arrows) and large amplitude bAHP at the soma. The doublet pair in dendrites consists of a full dendritic spike and a partial spike, followed by a smaller bAHP. One oscillation period is defined as the combined duration of the spike burst and subsequent bAHP (dashed lines below recording traces in $C$ ), and burst frequency as the inverse of oscillation period. 
( $n=10$ random samples). Direct current injection of -0.1 to $-0.5 \mathrm{nA}$ was applied when necessary to reduce spontaneous activity.

Pyramidal cells were antidromically activated using square wave stimulus pulses $(0.1 \mathrm{~ms})$ delivered via an isolation unit to a bipolar stimulating electrode consisting of twisted $62 \mu \mathrm{m}$ nichrome wire. Evoked activity was recorded and stored on a PC for offline analysis (CED, Cambridge, UK).

Tetrodotoxin (Alomone Labs, Israel) was focally ejected over the dendritic axis using electrodes of 1-2 $\mu \mathrm{m}$ tip diameter and $10-15 \mathrm{psi}$ according to the protocol detailed in Turner et al. (1994). Average values are indicated as mean $\pm \mathrm{SD}$ and statistical significance calculated using a Student's $t$-test or the Wilcoxon Signed Ranks test. Data plots were fit by a sigmoidal or Gaussian function using the software Microcal Origin.

\section{R E S U L T S}

The occurrence of burst discharge in ELL pyramidal cells has been reported under both in vitro and in vivo recording conditions (Gabbiani et al. 1996; Metzner et al. 1998; Turner et al. 1994, 1996). This study extends this work by examining the mechanisms for generating oscillatory spike bursts in both the soma and apical dendrites of pyramidal cells. In all cases, recordings were obtained from separate somatic or dendritic recordings. Figure $1 A$ illustrates that an oscillatory series of spike bursts could be evoked in either somatic or dendritic recordings using depolarizing current injection. Single spike bursts at the soma consisted of a series of spikes that steadily increased in frequency until generating a higher frequency spike doublet and bAHP. Bursts were most often comprised of 5-7 spikes near threshold but could consist of only spike doublets at the highest frequencies of burst discharge or at more depolarized membrane potentials. Since $\mathrm{Na}^{+}$spike discharge is initiated at the soma and backpropagates into apical dendrites (Turner et al. 1994), the basic pattern and frequency of oscillatory bursts were similar at the somatic and dendritic level. The primary difference was that the dendritic bAHP was smaller in amplitude than the somatic bAHP, or consisted of only a slow return of membrane potential to baseline over 10-20 ms.

Oscillatory discharge in pyramidal cells is thus defined as the grouping of spike discharge into rhythmic bursts, with each burst ending in a spike doublet and bAHP. A spike doublet is defined as the shortest interspike interval within a spike train, which was always followed by a bAHP. This study focuses on the soma-dendritic interaction that promotes a shift in spike afterpotentials during repetitive spike discharge and the manner in which a spike doublet contributes to burst termination.

A schematic diagram depicting how a backpropagating spike influences somatic membrane excitability is shown in Fig. $1 B$. $\mathrm{Na}^{+}$spike discharge is initiated near the cell body and is followed by spike backpropagation through $\sim 200 \mu \mathrm{m}$ (approximately one-third) of the apical dendritic arborization. The somatic spike is of narrow duration while the dendritic spike rapidly increases in duration with distance from the soma. As a result, current associated with dendritic spike discharge sources back to evoke a DAP at the soma that is superimposed on the somatic fast AHP (fAHP) and slow AHP (sAHP) (Turner et al. 1994). It is important to emphasize that this mechanism predicts that the DAP is generated primarily by electrotonic conduction during backpropagation of the spike from soma to dendrite, and not by a spike propagating in a return fashion from dendrite to soma. We have also established that the DAP in pyramidal cells is not generated by a $\mathrm{Ca}^{2+}$ dependent current or by synaptic potentials (Azouz et al. 1996;
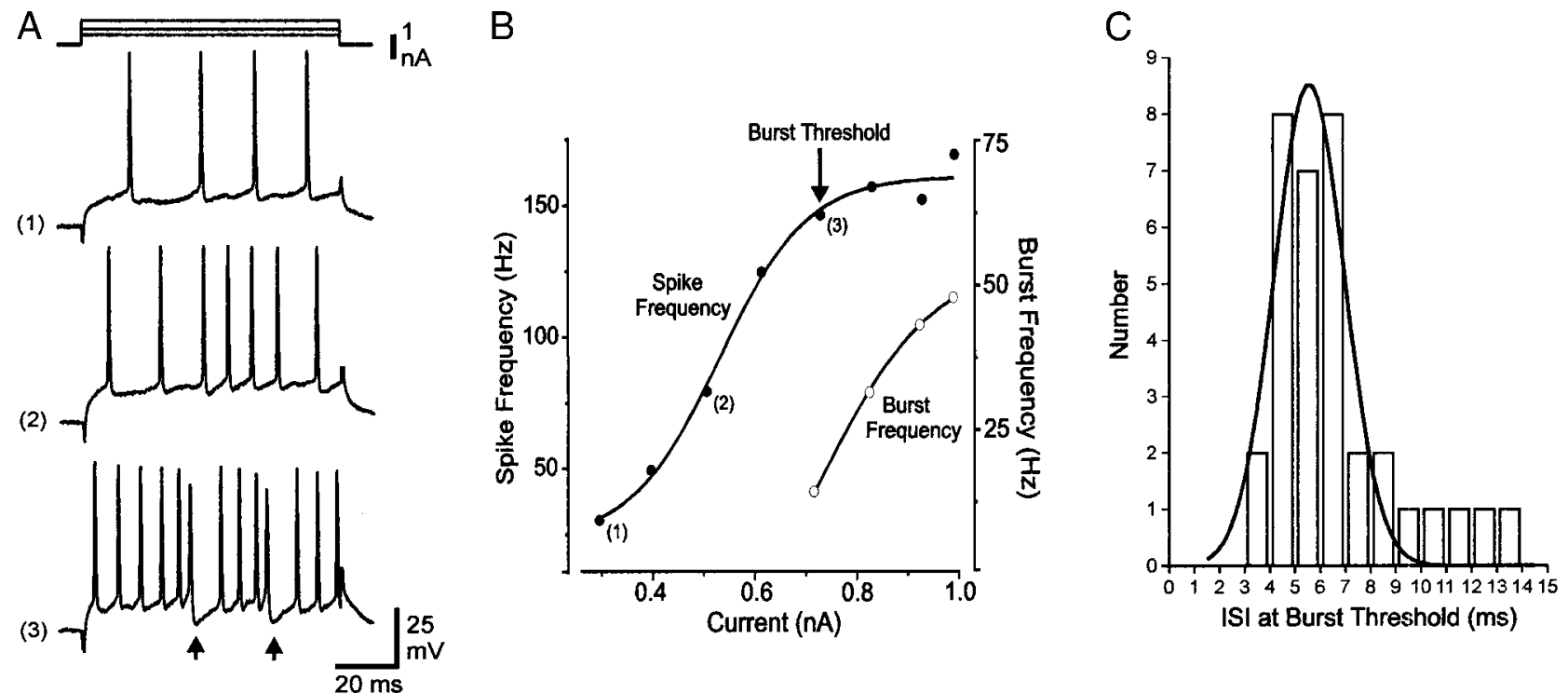

FIG. 2. Intensity-dependent shift in spike output from a tonic to burst discharge. $A$ : representative pyramidal cell somatic recording exhibits a shift from tonic to burst output as the level of depolarizing current injection is increased (bAHPs separating spike bursts are denoted by arrows). Numbers to the left of the recordings correspond to the positions indicated on the spike frequency/current $(F / I)$ plot shown in $B . B: F / I$ plot of spike discharge (•) for the somatic recording shown in $A$ with the threshold for transition to burst output marked by an arrow ( $80 \mathrm{~ms}$ current pulse). Also shown is the frequency of oscillatory spike bursts (○) once burst threshold was attained. The $F / I$ curves were fit by a sigmoidal function. $C$ : interval histogram of the average interspike interval in somatic and dendritic recordings at burst threshold (excluding spike doublet ISIs), indicating that the transition to burst output was strongly associated with interspike intervals of 3-7 ms. Data in $C$ were fit by a Gaussian function to a peak value of $5.5 \pm 1.38 \mathrm{~ms}(n=32 \mathrm{soma} ; n=11$ dendrites; binwidth $=1)$. 


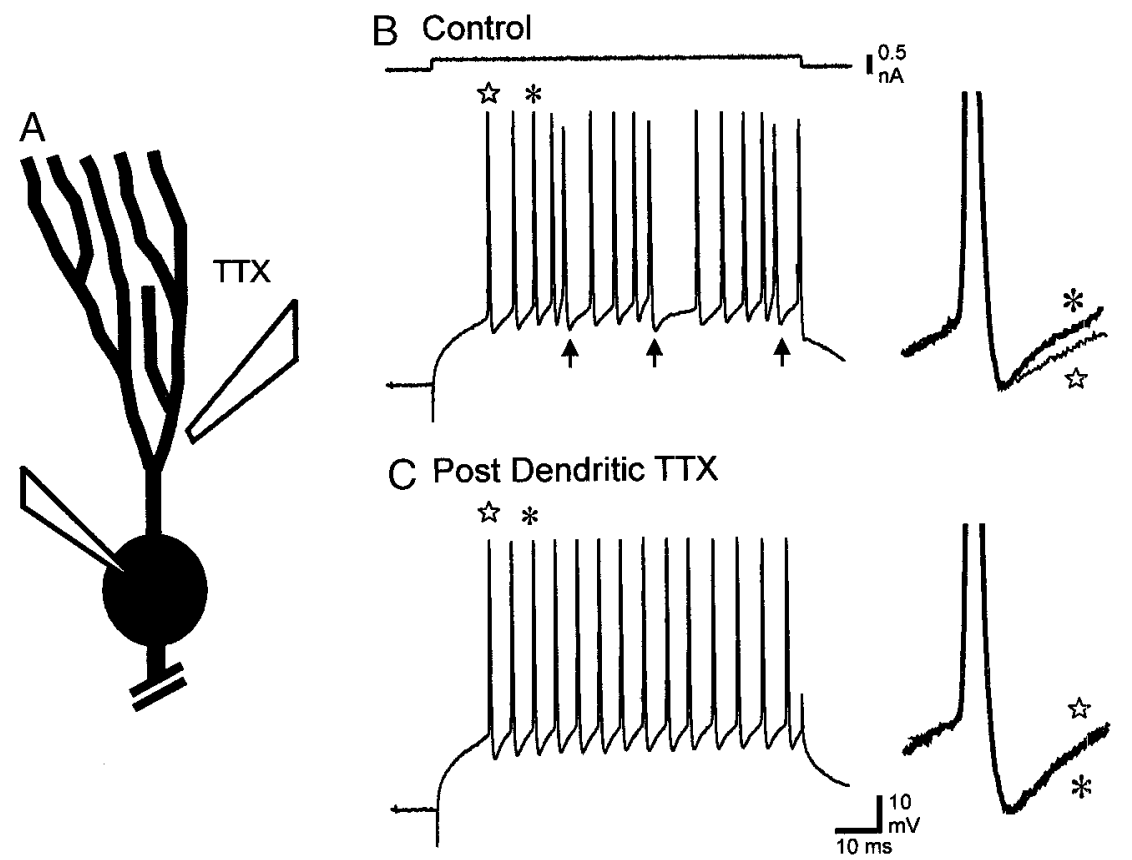

FIG. 3. Somatic AHPs are stable during repetitive spike discharge. A: schematic diagram of a pyramidal cell indicating a somatic recording site and repeated pressure ejections of TTX $(10 \mu \mathrm{M})$ in the apical dendritic region to block dendritic spike discharge and the DAP. $B$ : currentevoked spike bursts prior to TTX ejection indicating an apparent change in both AHP and DAP amplitudes during spike bursts (bAHPs are denoted by arrows). Inset: magnified and superimposed view of the first spike (is, narrow trace) and third spike (*, thick trace) of the indicated burst. $C$ : spike discharge and AHPs recorded immediately prior to TTX diffusion to the cell body layer, ensuring a complete block of backpropagating dendritic spikes and the DAP. Note the lack of change in AHP characteristics when recorded in isolation of dendritic activity (inset).

Bourque 1986; Higashi et al. 1993; Steriade et al. 1998; White et al. 1989), because focal somatic or dendritic ejections of the general $\mathrm{Ca}^{2+}$-channel blocker $\mathrm{Cd}^{2+}(400 \mu \mathrm{M})$ do not reduce

the DAP $(n=9)$. In addition, we have no evidence for the existence of $I_{\mathrm{h}}$ in ELL pyramidal cells that could contribute to burst discharge. Rather, the source of current for the DAP

A Soma

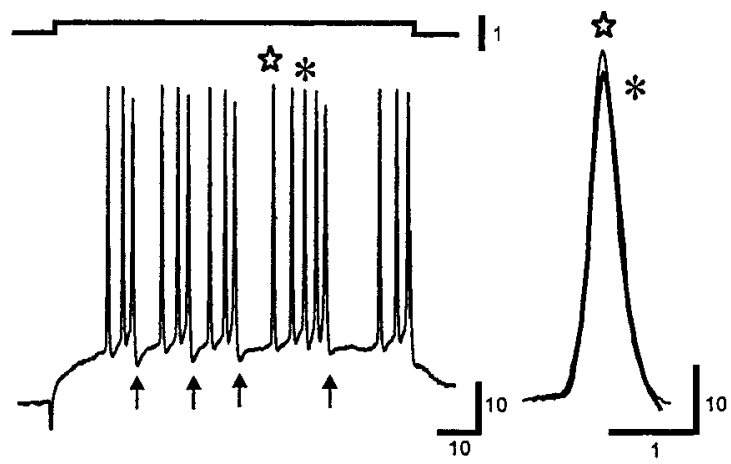

B Dendrite

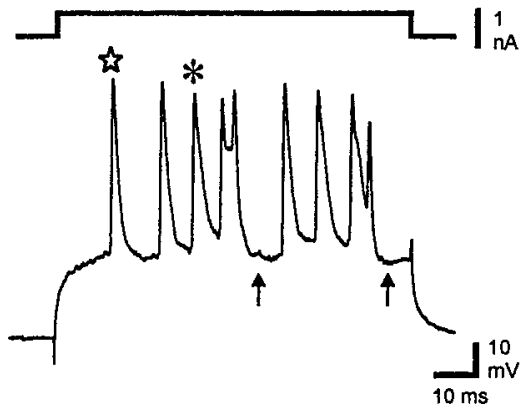

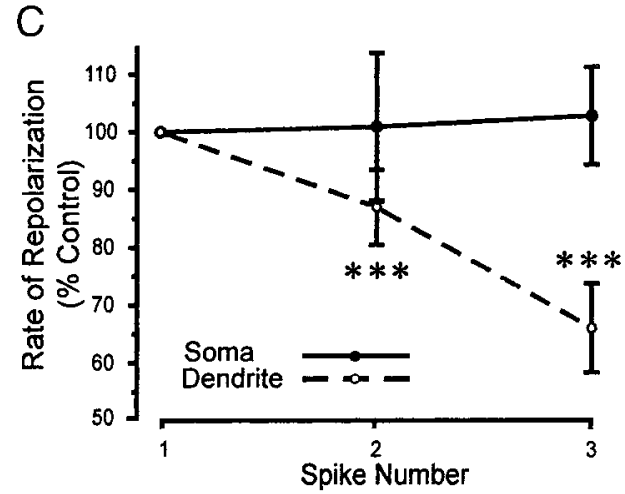

$\mathrm{D}$

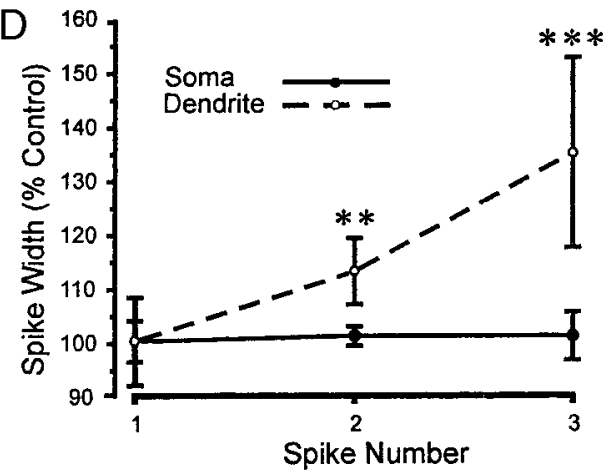

FIG. 4. Repetitive discharge selectively alters dendritic spikes. A: somatic recording exhibiting several spike bursts in response to current injection (bAHPs denoted by arrows). Inset: expanded and superimposed views of the first (thin trace) and third somatic spike (thick trace) in the indicated burst. Note the lack of change in spike repolarization and width during burst discharge. $B$ : separate dendritic recording illustrating 2 current evoked spike bursts. In contrast to the soma, there is a substantial decrease in the rate of repolarization and increase in dendritic spike duration during a burst [inset superimposes the first (thin trace) and third dendritic spike (thick trace) in the indicated burst]. $C$ and $D$ : plots of the mean rate of spike repolarization $(C)$ and spike width $(D)$ during spike bursts in the recordings shown in $A$ and $B$ (excluding spike doublets). These plots indicate a select and marked change in dendritic spike properties ( $* * P<0.05$; $* * * P<0.001$ in comparison to controls; $n=7$ somatic bursts, $n=8$ dendritic bursts). Spike width was measured at a time corresponding to $10 \%$ of spike amplitude. 
originates with the backpropagating TTX-sensitive $\mathrm{Na}^{+}$spike (Turner et al. 1994).

Pyramidal cells respond to depolarizations near spike threshold with a relatively tonic discharge of $\mathrm{Na}^{+}$spikes in the pattern of an initial lag and subsequent increase in frequency (Fig. 1C) (Mathieson and Maler 1988). This resulted from a shift in the balance between depolarizing and hyperpolarizing spike afterpotentials that was most visible for somatic recordings, where the peak amplitude of the fAHP and sAHP decreased while the peak amplitude of the DAP increased with successive spikes. This produced a net shift in membrane potential of up to $5.3 \mathrm{mV}$ during burst discharge at the soma $(2.8 \pm 1.4 \mathrm{mV} ; n=9)$. As previously reported, dendritic spikes were of smaller amplitude and longer duration compared with the soma, with only a small sAHP (Turner et al. 1994). Repetitive discharge converted the small dendritic sAHP to a net depolarization of up to 9.8 $\mathrm{mV}(6.2 \pm 2.84 \mathrm{mV} ; n=9$; Fig. $1 C)$. Following the bAHP, the amplitude of both fast and slow AHPs partially recovered by the first spike of the next burst, allowing the process to begin again (Fig. 1, $A$ and $C$ ).

\section{Factors determining burst threshold}

The ability for pyramidal cells to generate spike bursts was assessed by constructing frequency/current $(F / I)$ plots of spike discharge $(n=70)$. Since we found that the pattern and frequency of discharge was entirely equivalent in somatic and dendritic recordings, these numbers have been pooled in the following analyses. Near spike threshold, pyramidal cells responded to current injection with a relatively tonic pattern of single spike discharge (Fig. 2A). As depolarizing current was increased (0.1-1.2 nA), 61\% of recordings shifted from tonic to burst discharge, revealing an intensitydependent shift in the pattern of spike output $(n=43 / 70)$. Although some cells exhibited burst discharge on initial spike generation, there was typically a threshold for the transition to burst discharge corresponding to $\sim 70 \%$ of the maximum spike frequency attained on $F / I$ plots (Fig. $2 B$ ). Burst frequency at this threshold was consistently between $10-60 \mathrm{~Hz}(34 \pm$ $10.8 \mathrm{~Hz} ; n=28)$ and increased to $\sim 50-130 \mathrm{~Hz}(76 \pm 35.3$ $\mathrm{Hz} ; n=28$ ) at the maximum range of $F / I$ plots (Fig. $2 B$ ). By comparison, spike frequency (not including the spike doublet) ranged between $25-60 \mathrm{~Hz}$ at spike threshold and 123$475 \mathrm{~Hz}$ at the highest levels of current injection. An interval histogram of the average interspike interval (ISI) at burst threshold revealed that bursts were evoked when the ISI fell within $\sim 3-7 \mathrm{~ms}(5.5 \pm 1.38 \mathrm{~ms} ; n=34$; Fig. $2 C)$. These studies indicate that pyramidal cell output shifts to an oscillatory series of spike bursts once spike frequency exceeds $\sim 140 \mathrm{~Hz}$.

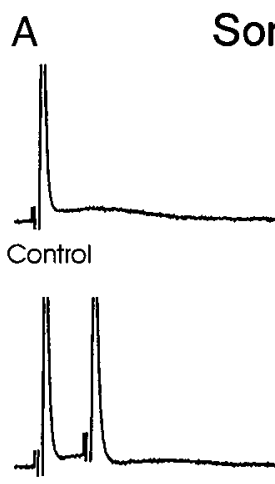

$3.0 \mathrm{~ms} \mathrm{C}-\mathrm{T}$
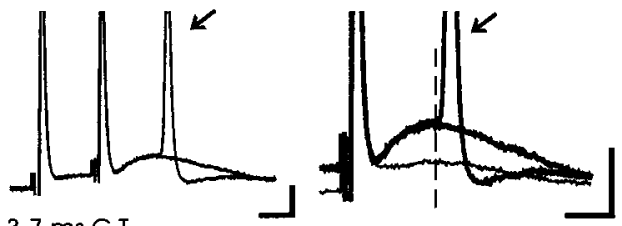

$3.7 \mathrm{~ms} \mathrm{C}-\mathrm{T}$

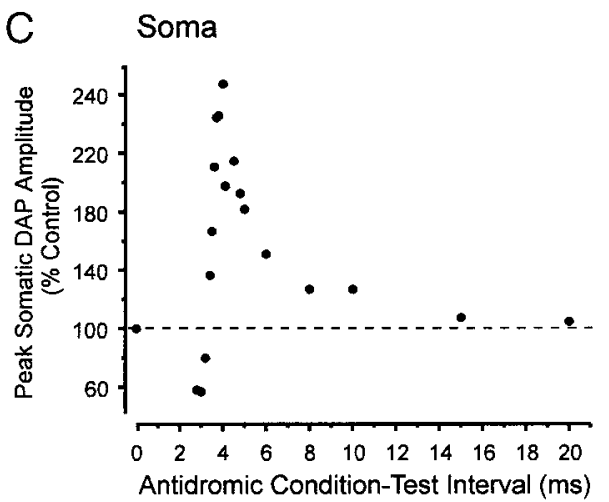

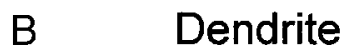
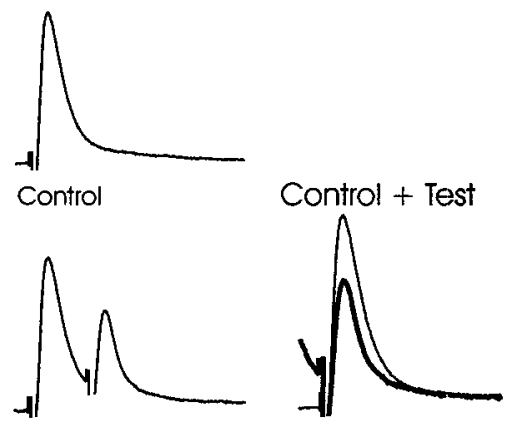

$3.7 \mathrm{~ms} \mathrm{C}-\mathrm{T}$
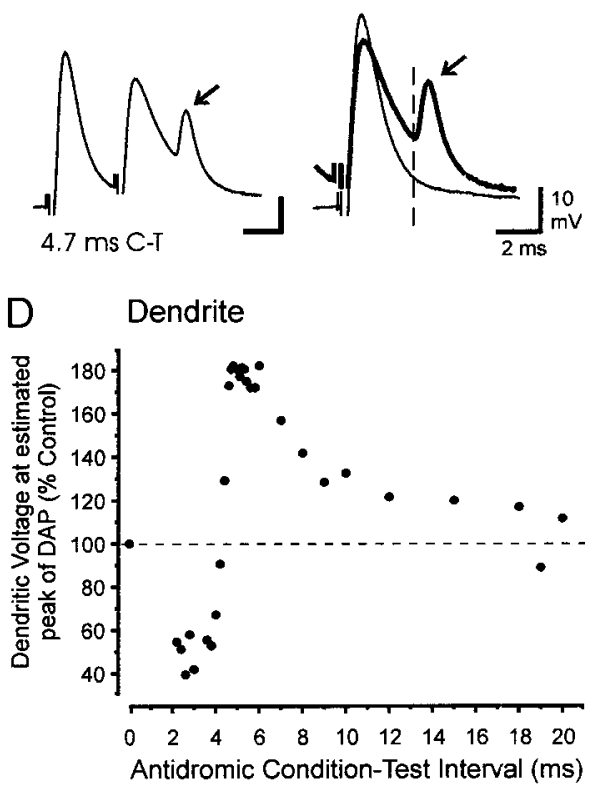

FIG. 5. The somatic DAP and dendritic spike depolarization exhibit frequency-dependent potentiation. $A$ and $B$ : representative series of antidromic stimulus pairs delivered at the indicated condition-test (C-T) intervals in separate somatic and dendritic recordings. Insets: expanded and superimposed views of control (thin trace) and test (thick trace) responses. Stimulus artifacts were reduced for illustrative purposes. At the soma $(A)$, a C-T interval of $3.0 \mathrm{~ms}$ selectively reduced DAP amplitude (middle). A C-T interval of $3.7 \mathrm{~ms}$ markedly potentiated the DAP, effectively triggering a spike doublet (bottom; slanted arrows denote second spike of the doublet; 2 sweeps are shown superimposed). In a dendrite $(B)$, C-T intervals of less than $\sim 4.9$ ms gradually reduced dendritic spike amplitude to a minimum at $3.0 \mathrm{~ms} \mathrm{C}-\mathrm{T}$, revealing a small partial spike reflected from the soma (middle). At a C-T interval of $4.7 \mathrm{~ms}$ the dendritic spike duration was increased and a spike doublet was triggered (arrows in bottom traces denote the second component of the spike doublet). $C$ and $D$ : plots of the absolute voltage of the somatic DAP and dendritic response at varying antidromic C-T intervals. The latency for measurement was fixed at the estimated peak of the somatic DAP ( $A$ and $B$, dashed lines in bottom). Note the close correspondence between the absolute voltage attained in the dendritic recording and somatic DAP amplitude, including a gradual reduction at shorter C-T intervals. Some increase in DAP amplitude and dendritic voltage can still be detected on test pulses at $>15 \mathrm{~ms}$ C-T intervals. 
Changes in somatic spike afterpotentials during repetitive discharge

Given the clear change in spike afterpotentials during repetitive discharge (Fig. 1C), we examined more closely the underlying basis for the change in AHP and DAP amplitudes that lead to the generation of a spike doublet.

AHPS. Superimposition of the DAP on the somatic AHPs prevented us from quantifying changes in the AHP in intact cells. We therefore sought a method to "isolate" somatic AHPs from the DAP. We have previously shown that the somatic DAP can be reduced by focally ejecting TTX in the middendritic region (Turner et al. 1994). However, these earlier experiments did not attempt to block discharge of all dendritic $\mathrm{Na}^{+}$spikes, including those in the most proximal dendrites. We therefore expanded on this approach to block all spike backpropagation to examine somatic AHPs in the absence of a DAP. To ensure that all dendritic activity was blocked, we continued TTX ejections until TTX had diffused to the cell layer and affected the somatic spike. By restricting our measurements to those records obtained immediately prior to this time, we were able to examine somatic AHPs in relative isolation.

Repeated ejections of TTX $(10-15 \mu \mathrm{m})$ in the dendritic region blocked the DAP and prevented the shift in membrane potential necessary to generate a spike doublet and bAHP, effectively blocking burst discharge (Fig. 3). This established that both the somatic fAHP and sAHP were very stable in amplitude and duration throughout a repetitive spike train (Fig. $3 C ; n=5)$. These data are important in revealing that somatic AHPs do not contribute to the change in afterpotentials observed during repetitive discharge through either a cumulative inactivation of underlying currents, or by a shift in $E_{\mathrm{K}}$. We were unable to perform a similar test on the dendritic sAHP. However, the experiments illustrated in Fig. 3 indicate that the majority of the somatic depolarizing shift during burst discharge can be attributed to changes in the DAP.

We were also interested in determining whether the increase in DAP amplitude during repetitive spike discharge influenced spike output. For this, we compared the interspike interval between the first pair of spikes with the last pair of spikes immediately preceding the spike doublet and found a statistically significant increase in spike frequency during burst discharge in control conditions $(P<0.0001 ; n=5$; Wilcoxon Signed Ranks test). However, this increase in frequency during a spike train was lost after the dendritic TTX ejections that blocked burst discharge $(P<0.077 ; n=5$; Wilcoxon Signed Ranks test). This indicates that the change in DAP amplitude during repetitive discharge has a measureable effect in increasing spike discharge frequency during a burst.

DAP. Based on the mechanism illustrated in Fig. $1 B$, one can predict that an increase in the degree of dendritic depolarization during a burst will enhance DAP amplitude at the soma. We therefore compared somatic and dendritic spikes during burst discharge. This revealed no significant decrease in so-
A Dendrite
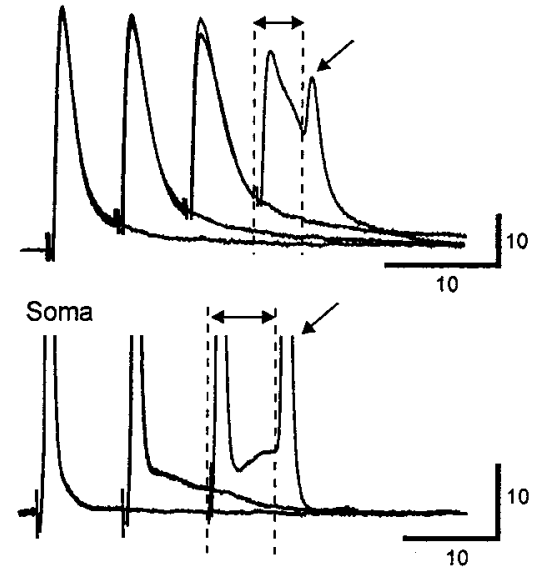

C
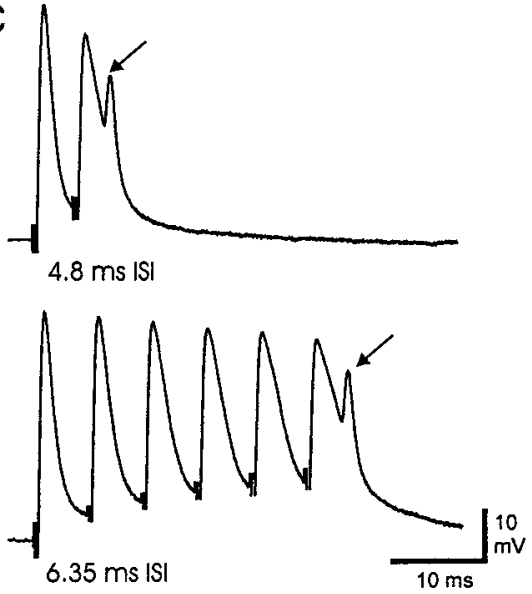

$\mathrm{B}$
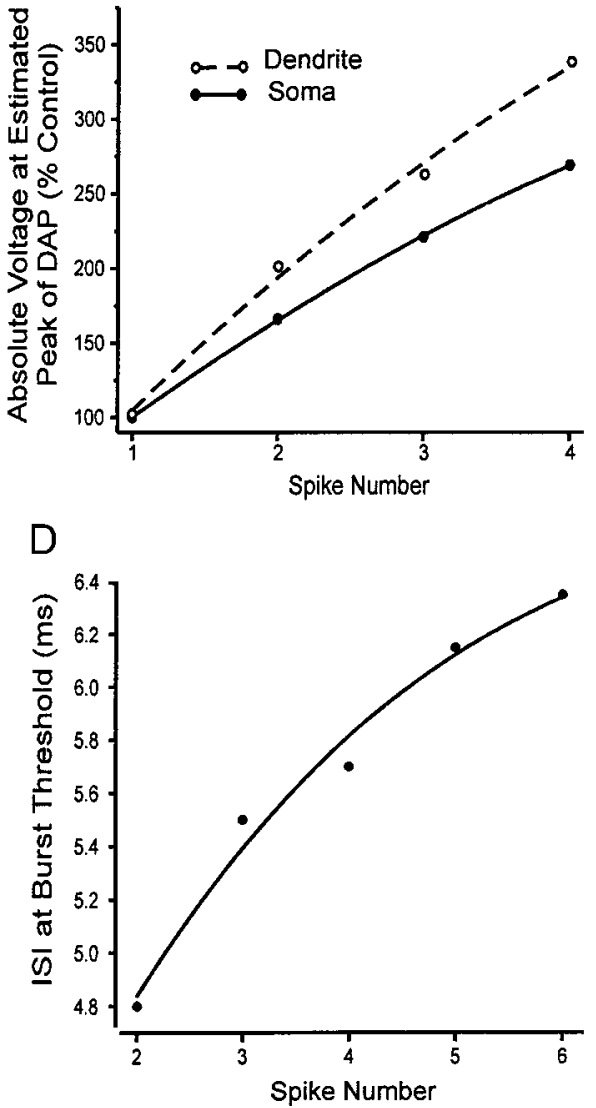

FIG. 6. Repetitive spike discharge summates dendritic spikes and lowers the threshold for burst generation. $A$ : antidromic stimulus trains in separate dendritic and somatic recordings evoked with an interspike interval (ISI) that triggers a spike doublet (slanted arrows; $6.0 \mathrm{~ms}$ ISI in dendrite, $9.1 \mathrm{~ms}$ ISI in soma). Records are shown superimposed for stimulus trains with an increasing number of stimuli. Somatic spikes are truncated. Note the summation of dendritic spikes, the increase in dendritic spike width, and the marked increase in DAP amplitude during repetitive discharge. $B$ : plots of the absolute dendritic membrane potential $(O)$ and DAP amplitude (•) during repetitive antidromic stimulation. Measurements were made at the estimated peak latency of the DAP that triggered the spike doublets in $A$ ( $A$, dashed lines and double arrows). $C$ and $D$ : dendritic spike summation during repetitive discharge permits a lower interspike interval to trigger a spike doublet (defined as burst discharge). $C$ : two antidromic stimulus trains ( 2 and 6 stimuli) illustrating the longest interspike interval that was capable of triggering a spike doublet (arrows). $D$ : plot of the longest interspike intervals capable of evoking a spike doublet as the antidromic dendritic stimulus train in $C$ was increased from 2 to 6 spikes. Lines in $B$ and $D$ represent best fit sigmoidal curves. Stimulus artifacts were reduced for illustrative purposes. 
matic spike amplitude (92 $\pm 7.9 \%$ of control; $n=9$ ) and no change in the rate of somatic spike repolarization or duration over the time course of a single burst (Fig. 4, $A$ and $C$ ). In contrast, dendritic spikes exhibited a significant decrease in amplitude during a burst $(65 \pm 11.7 \%$ of control; $n=9 ; P<$ 0.001 , Student's $t$-test), as well as a substantial change in the rate of repolarization and duration (Fig. 4B). By the third spike of a burst, the rate of repolarization of dendritic spikes could decrease to $66 \%$ of control values while spike duration increased up to $135 \%$ (Fig. $4, C$ and $D$ ).

Since pyramidal cells exhibit a gradual increase in spike frequency during repetitive discharge, we examined the possibility that the increase in dendritic spike width during a burst was frequency-dependent. These experiments employed antidromic stimulus pairs delivered at varying condition-test (C-T) intervals to determine any frequency-dependent change in the DAP or dendritic spike. As shown in Fig. 5, there was a pronounced effect on both the DAP and dendritic spike over a specific range of $\mathrm{C}-\mathrm{T}$ intervals.

At the soma, short antidromic C-T intervals of $\sim 2.2-2.9 \mathrm{~ms}$ fell within the spike refractory period and blocked spike discharge (not shown). C-T intervals of 2.9-3.2 ms evoked a somatic spike but reduced DAP amplitude on the test response (Fig. 5A;n=8), an effect which could be seen as an all-ornone phenomenon in some cases. In contrast, C-T intervals of $\sim 3-7 \mathrm{~ms}$ markedly potentiated the DAP by up to $500 \%$ (Fig. $5 C$ ). As the potentiated DAP was often large enough to reach spike threshold, a spike doublet was effectively evoked at these C-T intervals (Fig. 5A; bottom). DAP potentiation was most apparent in terms of absolute amplitude but could also be detected as an increase in duration. Measurements of peak DAP amplitude revealed an average maximal increase of $262 \pm 121 \%$ between $2.6-5.5 \mathrm{~ms} \mathrm{C}$-T intervals $(n=8)$, which decreased to $120 \pm 13 \%(n=8)$ at a $10 \mathrm{~ms} \mathrm{C}-\mathrm{T}$ interval. The potentiation of DAP amplitude gradually decreased at longer C-T intervals, but was still present in one case at $134 \%$ at a 60 ms C-T interval. It is important to note that none of the observed effects on DAP amplitude can be attributed to recurrent or network activation of synaptic responses, as pyramidal cell axons exhibit no recurrent collateral projections (Maler 1979; Maler et al. 1981). Furthermore, $\mathrm{Cd}^{2+}$ ejections (400 $\mu \mathrm{M})$ at the somatic or dendritic level do not decrease DAP amplitude $(n=9)$.

In dendritic recordings antidromic C-T intervals of 3.0-4.5 $\mathrm{ms}$ evoked the test response on the falling phase of the control dendritic spike, and near the dendritic spike refractory period. As a result, the amplitude of the test dendritic spike was gradually reduced as $\mathrm{C}-\mathrm{T}$ intervals were shortened to $\sim 4.5-3.0$ ms. At the shorter of these C-T intervals a small partial spike of $26.6 \pm 9.5 \mathrm{mV}$ and $2.4 \pm 0.4 \mathrm{~ms}(n=8)$ was uncovered (Fig. 5B, middle). Earlier work has established that this partial spike is due to the passive reflection of a spike discharged at the soma (Turner et al. 1994). In agreement with this, C-T intervals of $\sim 2.1-2.9 \mathrm{~ms}$ blocked the small partial spike in dendrites in an all-or-none manner; intervals that are within the somatic spike refractory period. As C-T intervals fell near $\sim 4.5 \mathrm{~ms}$, dendritic spike amplitude began to approach control values but exhibited a substantial decrease in the rate of repolarization and an increase in duration. This produced a temporal summation of the spike pair, and often resulted in the discharge of a spike doublet on the test response, as indicated by the presence of a small partial spike (Fig. $5 B$, bottom). We determined that the onset latency of this partial spike $(\sim 3-4$ $\mathrm{ms}$ ) coincided with an average increase of $158 \pm 46.3 \%$ in the absolute voltage shift on the test dendritic spike $(n=8 ; P<$ 0.01; Wilcoxon Signed Ranks test; Fig. 5D). This gradually declined with longer C-T intervals, but could still be detected in some recordings at C-T intervals as long as $20 \mathrm{~ms}$ (Fig. 5D). Importantly, there was a close correspondence between changes in somatic DAP amplitude and dendritic spikes over a wide range of C-T intervals (cf. Fig. 5, $C$ and $D$ ).

The changes in DAP amplitude and dendritic spike waveforms identified for paired stimuli continued to accumulate during repetitive spike discharge. As shown in Fig. 6A, the temporal summation of dendritic spikes and increase in DAP amplitude steadily increased during an antidromic stimulus train. This led to the generation of a spike doublet, as evidenced by a full amplitude spike pair at the soma and a spike followed by a small partial spike in dendrites. We found that three to four antidromic stimuli delivered at $150-200 \mathrm{~Hz}$ evoked increases of up to $350 \%$ in peak DAP amplitude and $250 \%$ in the absolute dendritic potential at the estimated peak of the somatic DAP (Fig. 6B). Furthermore, summation of dendritic spikes during repetitive stimulation affected the threshold for burst discharge, as indicated by the generation of a spike doublet. Thus the frequency capable of evoking a burst decreased with the number of spikes in an antidromic stimulus train (Fig. 6, $C$ and $D$ ).

It is important to note that the C-T intervals tested in the
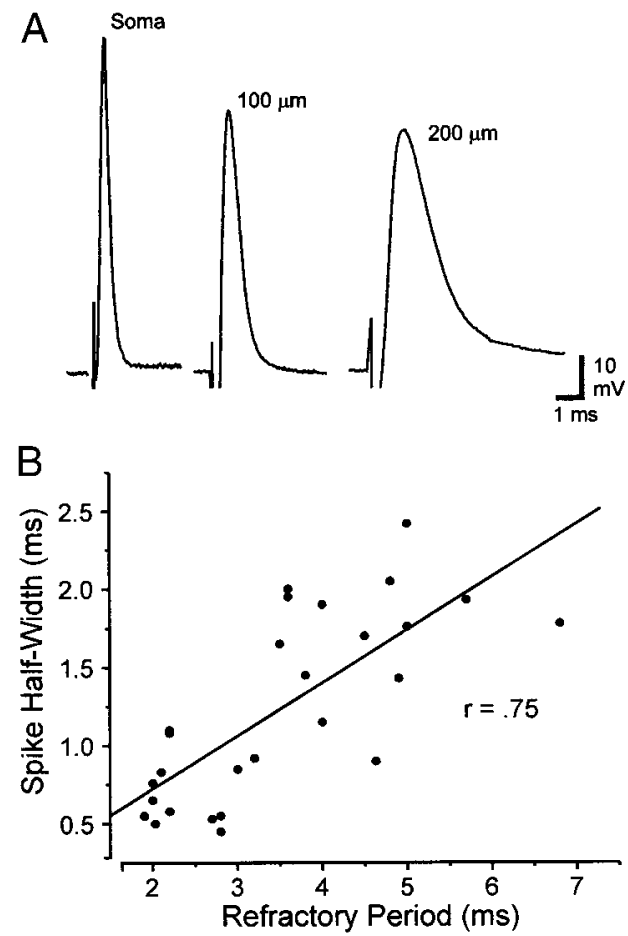

FIG. 7. Refractory period increases with distance from the soma. A: representative examples of antidromically evoked spike discharge in separate recordings obtained at the soma, or in dendrites at 100 and $200 \mu \mathrm{m}$ from the soma. Note the decrease in spike amplitude and increase in duration with distance from the soma. $B$ : scatter plot of relative refractory periods measured with antidromic stimulus pairs at all locations with respect to spike half-width $(n=27)$. Note the positive correlation coefficient between refractory period and measured spike half-widths $(r=0.75 ; P<0.0001 ; n=27)$, indicating an increase in refractory period with distance from the soma. 
above experiments are of direct relevance to the ISIs encountered during burst discharge. Sequential analysis of repetitive spike discharge reveals that ISIs at the beginning of a currentevoked burst fell between 5-16 ms and shortened to 3-7 ms just prior to generation of a spike doublet. The ISI values during burst discharge are thus within the range which potentiate the DAP and produce a change in dendritic spike properties (Figs. 5 and 6). Moreover, the antidromic C-T intervals used to increase dendritic and somatic depolarizations experimentally were evoked with a constant antidromic ISI. One could expect the changes in somatic and dendritic responses to be even more pronounced under normal conditions in which the ISI decreases with each spike in a burst.

\section{Spike doublets and burst termination}

Since spike discharge is grouped into bursts by the recurring generation of a spike doublet and bAHP, the spike doublet may act to inhibit the soma-dendritic process driving spike discharge. As indicated above, the second spike of the doublet in dendrites was only a small partial spike, suggesting a failure of dendritic spike invasion. In this regard, Turner et al. (1994) reported different refractory periods for somatic and dendritic spikes in ELL pyramidal cells. This was confirmed in the present study, although we also noted a wide range of refractory periods for dendritic recordings. Figure $7 A$ provides representative recordings of spike discharge at the soma over the distance spikes backpropagate in pyramidal cell dendrites. This illustrates a decrease in spike amplitude and an increase in spike duration with distance from the soma that could alter refractory period. Indeed, a plot of relative refractory period measured at all locations revealed progressively longer refractory periods as spike width increased from $\sim 2 \mathrm{~ms}$ (somatic recordings) to $6.8 \mathrm{~ms}$ (distal dendritic recording) (Fig. $7 B ; n=$ 27). This would help account for why dendritic spike amplitude decreased gradually as antidromic C-T intervals were reduced below $\sim 4.5 \mathrm{~ms}$ (Fig. $5 D$ ). Spike discharge in the more distal dendritic sites that are associated with a long refractory period would be blocked by relatively long C-T intervals compared with proximal dendritic sites with shorter refractory periods. The progressive block of distal dendritic sites would thus remove a percentage of the dendritic depolarization recorded at more proximal sites.

The average value for relative refractory period at the soma was $2.6 \pm 0.64 \mathrm{~ms}(n=12)$. By defining the dendritic refractory period as the $\mathrm{C}$-T interval that evoked the smallest partial spike in recordings $\geq 100 \mu \mathrm{m}$ from the soma, we arrived at an average value of $4.5 \pm 0.93 \mathrm{~ms}(n=14)$. By comparison, the average ISI for spike doublets measured at the soma was $3.9 \pm 1.08 \mathrm{~ms}(n=12)$. These average values are consistent with the interval of the spike doublet falling inside the dendritic refractory period. However, given the increase in refractory period over the cell axis we specifically tested the relationship between spike doublet interval and spike refractory period in a set of individual recordings. These experiments compared the
A
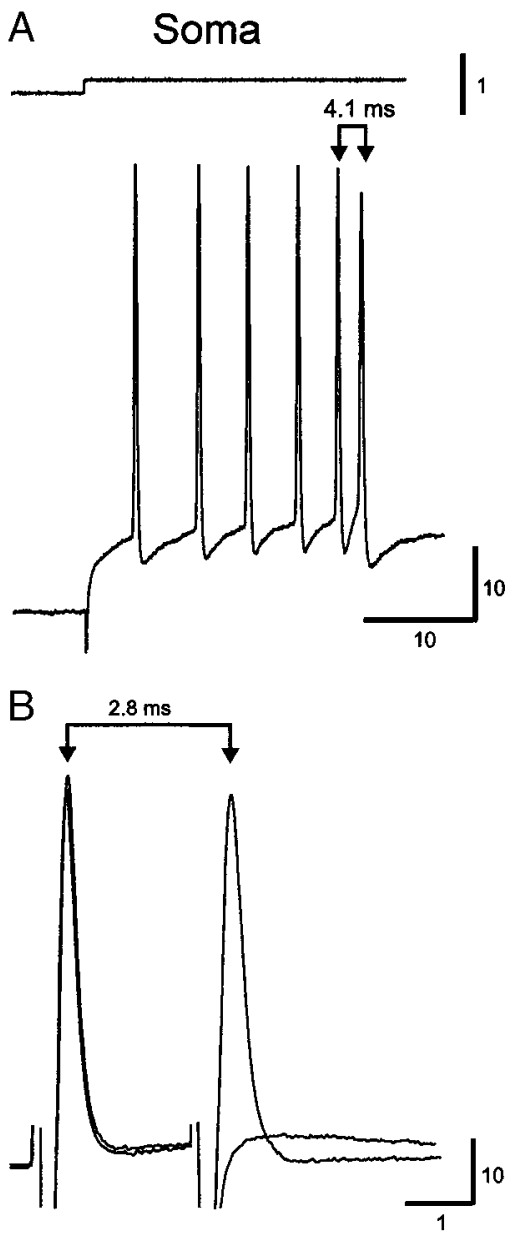

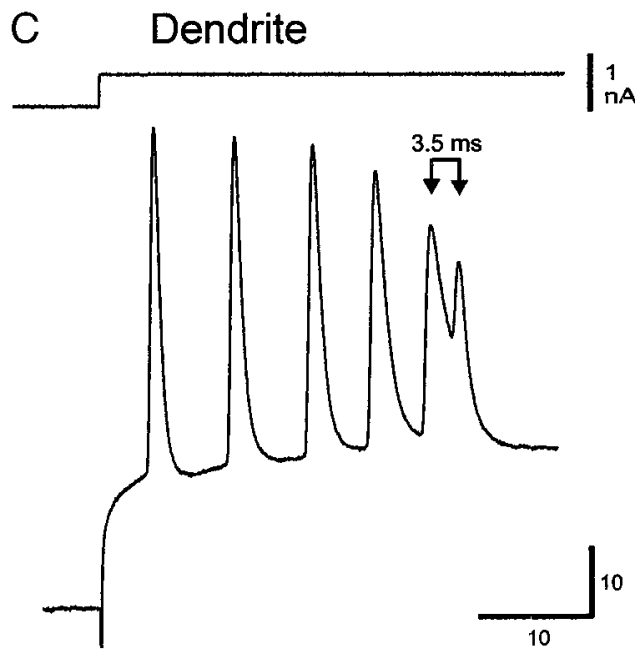

D

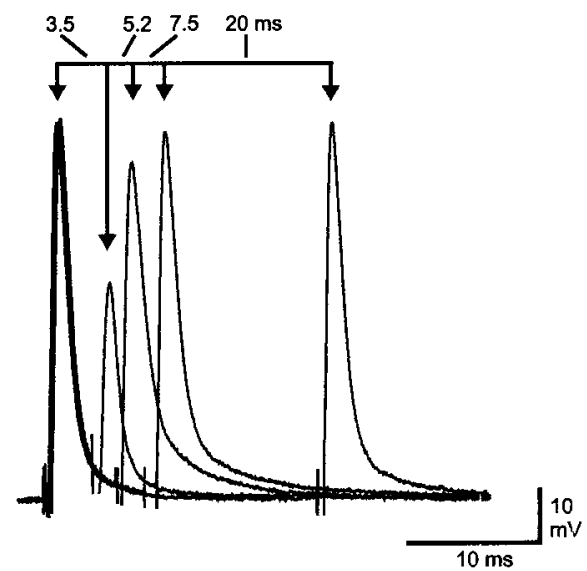

FIG. 8. The spike doublet ISI falls within the refractory period of dendritic spikes. $A$ and $B$ : somatic recording comparing the doublet ISI during current-evoked burst discharge to the spike refractory period. A: expanded view of a current-evoked somatic spike burst, indicating a spike doublet ISI of $4.1 \mathrm{~ms}$ (linked arrows). $B$ : antidromic C-T stimulus pairs in the somatic recording in $A$ indicate a relative refractory period of $2.8 \mathrm{~ms}$ as indicated by an allor-none failure of spike discharge on the second stimulus (traces superimposed). Note that the short somatic refractory period allows the spike doublet in $A$ with an ISI of $4.1 \mathrm{~ms}$ to be evoked as 2 full spikes. $C$ and $D$ : dendritic recording from another cell comparing the doublet ISI and dendritic spike refractory period. $C$ : expanded view of a current-evoked dendritic spike burst exhibiting a spike doublet ISI of $3.5 \mathrm{~ms}$ (linked arrows). $D$ : antidromic C-T stimulus pairs in this dendritic recording indicate that a $\mathrm{C}$ - $\mathrm{T}$ interval of $3.5 \mathrm{~ms}$ falls within the refractory period of the dendritic spike, revealing only a small partial spike (long arrow). Superimposing antidromic responses at progressively longer $\mathrm{C}-\mathrm{T}$ intervals illustrates an eventual return of dendritic spike amplitude. Antidromic stimulus artifacts were reduced for illustrative purposes. 
A Dendrite
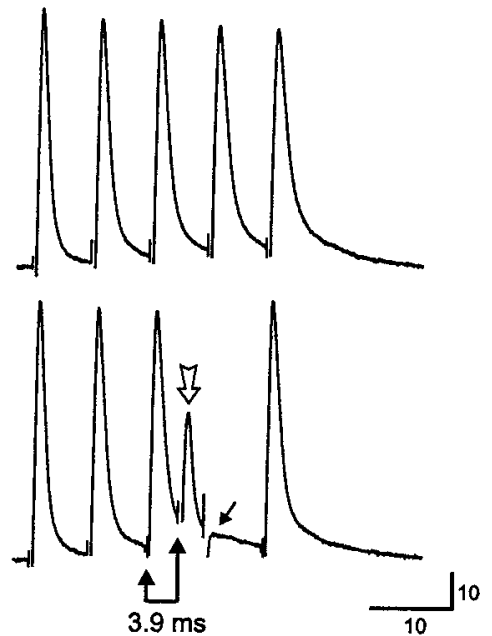

B Soma
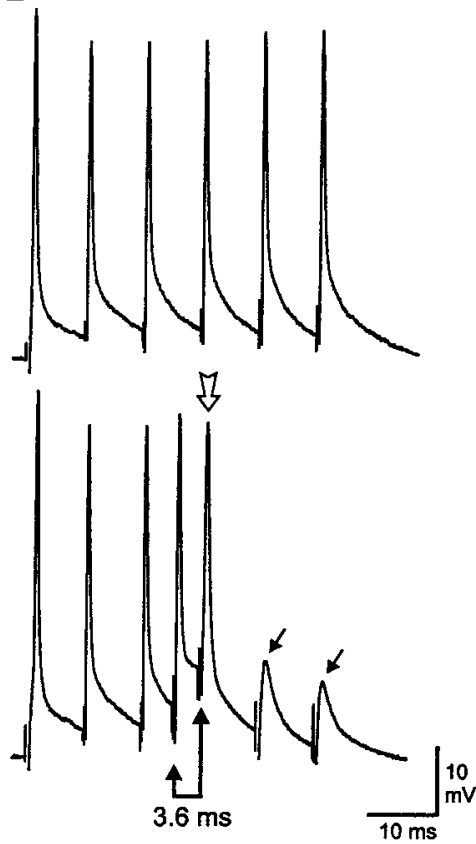

FIG. 9. Invoking a spike doublet inhibits spike discharge and triggers a bAHP. A, top: a dendritic recording illustrating a train of 5 antidromic spikes (7.1 ms ISI). Bottom: spike doublet is simulated by inserting an additional antidromic stimulus $3.9 \mathrm{~ms}$ after the 3rd spike in the train (linked solid arrows). The new stimulus fell within the refractory period of the dendritic spike, evoking only a small partial spike (open arrow) and inhibited discharge of the next spike in the train (slanted arrow). $B$, top: control antidromic stimulus train in a separate somatic recording (8 ms ISI). Bottom: spike doublet is simulated by inserting an additional antidromic stimulus (open arrow) $3.6 \mathrm{~ms}$ after the 4 th spike in the train. This evoked a full spike at the soma but inhibited subsequent spikes in the stimulus train (solid arrows indicate a partial spike corresponding to the presumed initial segment spike). Antidromic stimulus artifacts were reduced for illustrative purposes.

spike doublet ISI recorded during current-evoked burst discharge to the refractory period measured with antidromic stimulus pairs. This revealed that the ISI for spike doublets at the soma was consistently longer than the measured somatic spike refractory period in a given cell (difference of $0.96 \pm 0.78 \mathrm{~ms}$; $n=9 ; P<0.01$; Wilcoxon Signed Ranks test). As a result, the somatic spike doublet was made up of two full amplitude action potentials (Fig. 8, $A$ and $B$ ). In contrast, the spike doublet ISI measured in dendritic recordings always fell within the range of antidromic $\mathrm{C}-\mathrm{T}$ intervals that reduced dendritic spike amplitude (Fig. 8, $C$ and $D$; difference of $0.4 \pm 0.55 \mathrm{~ms} ; P<$ 0.05; Wilcoxon Signed Ranks test; $n=8$ ), suggesting a loss of spike backpropagation in some portion of the dendritic tree.

We tested whether a spike doublet could terminate a burst by simulating a spike doublet during an antidromic stimulus train (Fig. 9). This was accomplished by inserting an additional stimulus at varying latencies within an antidromic stimulus train of fixed ISI. In dendrites we found that the addition of an antidromic stimulus at latencies close to the dendritic refractory period produced only a small partial spike on the falling phase of the previous spike (Fig. 9A). This blocked the discharge of at least one subsequent dendritic spike of the background stimulus train, presumably through the actions of a bAHP. In contrast, an additional stimulus inserted at longer latencies evoked nearly-full sized dendritic spikes and no subsequent inhibition of spike discharge (data not shown). In somatic recordings, the insertion of an additional antidromic stimulus at effective C-T intervals of $\sim 3-5 \mathrm{~ms}$ evoked a spike doublet comprised of two full spikes followed by inhibition of subsequent spike discharge (Fig. 9B). The use of C-T intervals near the somatic spike refractory period resulted in failure of the imposed spike but no interruption of spike discharge in response to subsequent stimuli in the train. These experiments are important in
A Somatic Contribution
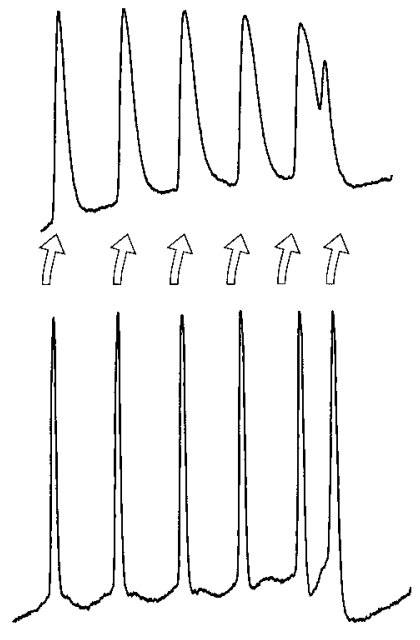

Dendritic Refractory Period $=4.5 \mathrm{~ms}$
B Dendritic Contribution

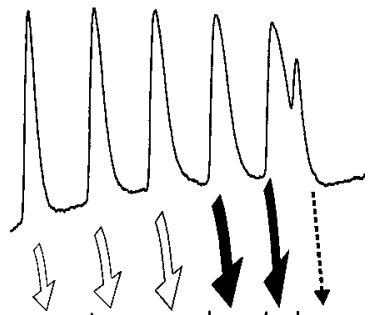

FIG. 10. Summary of working hypothesis of conditional backpropagation and burst discharge. $A$ and $B$ : representative spike bursts from separate pyramidal cell dendritic and somatic recordings. The records in $A$ depict the somatic contribution to dendritic activity during a burst, while records in $B$ illustrate the dendritic contribution to somatic depolarization during a burst. The weight of influence is shown by the size and shading of arrows. A: each successive somatic spike in a burst triggers a full spike capable of backpropagating into dendrites. $B$ : each successive dendritic spike in a burst is longer in duration than the last, progressively increasing current flow back to the soma (shaded arrows). There is a concurrent increase in DAP amplitude and duration until the DAP becomes large enough to reach threshold to trigger a spike doublet at the soma. The refractory period of dendritic membrane $(4.5 \mathrm{~ms})$ is longer than the ISI of the spike doublet $(3.0 \mathrm{~ms})$, preventing backpropagation of the second spike of the pair. This failure of dendritic spike discharge eliminates the dendritic depolarization that drives the spike burst (denoted by dashed arrow), and is followed by membrane repolarization by the bAHP. 
identifying the dendritic spike refractory period as a key factor controlling spike backpropagation at the end of a burst.

\section{Mechanism of burst generation}

Figure 10 illustrates our working hypothesis of how spike frequency establishes a process of conditional backpropagation to generate burst discharge. During repetitive spike discharge at ISIs greater than $\sim 8 \mathrm{~ms}$, there is a faithful backpropagation of each spike from soma to dendrite. Spike ISIs of $\sim 3-7 \mathrm{~ms}$ promote a selective broadening of dendritic spikes, allowing dendritic spikes to summate and exert a progressively greater influence on the soma as a DAP. As a result, the DAP increases in amplitude during a spike burst, ultimately reaching threshold to trigger a spike doublet at the soma. The spike doublet ISI falls outside of the somatic refractory period, allowing two full action potentials to be generated. The first of these spikes backpropagates into dendrites, but the second fails to backpropagate as it falls within the refractory period of dendritic spike discharge. The dendritic depolarization is thus abruptly removed from one spike to the next, allowing the cell to repolarize and terminate the burst. Repetition of this process acts to generate a rhythmic series of spike bursts separated by bAHPs.

\section{I S C U S S I O N}

This study describes a novel mechanism by which the success of dendritic spike backpropagation can generate oscillatory spike bursts in a central neuron. Specifically, we have shown that spike frequency imparts a process of conditional backpropagation which alternately increases or removes the influence of backpropagating spikes on somatic membrane potential to produce an oscillatory burst output.

\section{Frequency-dependent spike broadening}

A critical feature of this process is a frequency-dependent potentiation of the DAP. This was associated with a change in the rate of repolarization, duration, and temporal summation of dendritic spikes. Frequency-dependent broadening and summation of dendritic spikes is maximal for spike frequencies between $140-330 \mathrm{~Hz}$ (3-7 ms ISI), and controls burst threshold by regulating the transition from tonic to burst output (Fig. 2). The exact spike frequency capable of reaching this transition point depends on the number of spikes invoking dendritic spike summation (Fig. 6, $C$ and $D$ ). As a result, the immediate history of spike discharge can influence burst threshold. We would thus expect burst output to begin at even lower spike frequencies during the spontaneous activity ordinarily found in vivo (Gabbiani et al. 1996; Metzner et al. 1998). This is supported by the finding that spike bursts can be recorded in vivo without sensory stimulation at spontaneous discharge frequencies of $\sim 50 \mathrm{~Hz}$ (Metzner et al. 1998).

Frequency-dependent spike broadening has previously been reported in cell bodies, axons, and presynaptic terminals (Aldrich et al. 1979; Bourque 1991; Jackson et al. 1991; Ma and Koester 1995; Mathes et al. 1997; Quattrocki et al. 1994; Shao et al. 1999). This can involve a cumulative inactivation of A-type, delayed rectifying, or $\mathrm{Ca}^{2+}$-activated $\mathrm{K}^{+}$currents underlying spike repolarization, often with an associated increase of $\mathrm{Ca}^{2+}$ current with each $\mathrm{Na}^{+}$spike (Aldrich et al. 1979;
Borst and Sakmann 1999; Bourque 1991; Jackson et al. 1991; Klemic et al. 1998; Ma and Koester 1995; Quattrocki et al. 1994; Shao et al. 1999). Backpropagating $\mathrm{Na}^{+}$spikes can also activate dendritic $\mathrm{Ca}^{2+}$ currents in a manner dependent on spike frequency and conduction along the dendritic axis (Callaway and Ross 1995; Larkum et al. 1996; Spruston et al. 1995).

The selective change in dendritic spike repolarization found in ELL pyramidal cells during repetitive discharge may be due to differences in the density or subtype of $\mathrm{K}^{+}$channels in somatic versus dendritic regions, or their inactivation by the very different action potential waveforms in these two compartments. We can state that $\mathrm{Ca}^{2+}$-dependent currents do not appear to contribute to either spike broadening or the depolarizing shift in pyramidal cell dendrites, as $400 \mu \mathrm{M} \mathrm{Cd}^{2+}$ ejections in the dendritic region had no effect on these potentials $(n=3)$. Dendritic spike broadening thus results primarily from actions on TTX-sensitive dendritic $\mathrm{Na}^{+}$spikes and non- $\mathrm{Ca}^{2+}$ dependent repolarizing $\mathrm{K}^{+}$currents. The most likely factor we have identified thus far is a gymnotid homologue of the mammalian $\mathrm{Kv} 3.3 \mathrm{~K}^{+}$channel which is found throughout the dendritic arbor of pyramidal cells (Lemon et al. 1998; Morales et al. 1998; Rashid and Dunn 1998a,b). Given the established role for Kv3 channels in spike repolarization (Rudy et al. 1999), it will be important to determine the ability for Kv3 channels to contribute to dendritic spike broadening.

\section{Burst termination}

The generation of a somatic spike doublet provides an intrinsic mechanism to pattern spike discharge into bursts when the dendritic refractory period blocks spike backpropagation. A failure of backpropagating spikes to invade distal dendritic branches has been observed in other cells when repetitive discharge dramatically reduces dendritic spike amplitude (Colbert et al. 1997; Jung et al. 1997; Spruston et al. 1995). Synaptic inhibition can also regulate the degree of spike backpropagation (Buzsáki et al. 1996; Tsubokawa and Ross 1996). However, the mechanism we describe here differs substantially from these cases in representing an all-or-none failure of dendritic spike invasion at the level of proximal apical dendrites from one spike to the next. This conditional backpropagation is thus a novel soma-dendritic interaction, and the first consideration of the role for refractory periods in regulating dendritic spike discharge.

The exact location of dendritic spike failure cannot be identified. However, we have recorded dendritic spike failure in locations as close as $\sim 50 \mu \mathrm{m}$ from the cell layer, suggesting that dendritic refractory period increases at a minimal distance from the soma. The difference in somatic and dendritic spike refractory periods may result from a comparatively low density of $\mathrm{Na}^{+}$and $\mathrm{K}^{+}$channels in dendritic regions. The refractory period of spike discharge has in fact been shown to depend on $\mathrm{K}^{+}$conductances involved in spike repolarization (Massengill et al. 1997). This is further supported by the correlation between spike width and refractory period shown in Fig. 7. Failure of spike backpropagation would thus become more likely if cumulative inactivation of dendritic $\mathrm{K}^{+}$channels during a burst increased dendritic refractory period with respect to the spike doublet ISI. The failure of backpropagation would be further assured by a cumulative inactivation of den- 
dritic $\mathrm{Na}^{+}$channels (Colbert et al. 1997; Jung et al. 1997; Mickus et al. 1999), as suggested by the decline in dendritic spike amplitude during spike bursts.

The spike doublet was always followed by a bAHP that temporarily hyperpolarized the membrane after a spike burst. We have not fully determined the ionic mechanisms underlying this potential but find that the bAHP can be partially reduced by focal ejections of $\mathrm{Cd}^{2+}(400 \mu \mathrm{M})$ in the somatic $(n=4)$ but not dendritic region $(n=3)$. This would be consistent with an elevated $\mathrm{Ca}^{2+}$ entry on generation of a high-frequency spike doublet that is restricted to the somatic compartment. We are uncertain as to whether such a $\mathrm{Ca}^{2+}$ current accumulates during the spike train, or is generated only by the spike doublet. In either case, the magnitude of the bAHP will be more apparent upon the sudden loss of the DAP when spike backpropagation fails upon the second spike of the doublet. Given the potential role of the bAHP in regulating burst frequency, the ionic basis and distribution of channels underlying this response warrants further investigation.

\section{Functional significance}

Many neurons initiate $\mathrm{Na}^{+}$spike discharge near the soma which is followed by spike backpropagation over extensive regions of the dendritic arbor (Chen et al. 1997; Johnston et al. 1996; Larkum et al. 1996; Spruston et al. 1995; Stuart and Sakmann 1994; Stuart et al. 1997; Turner et al. 1991). The potential for dendritic spikes to directly depolarize somatic membrane during backpropagation was considered in some of the earliest reports of intracellular recordings (Calvin and Hartline 1977; Calvin and Sypert 1976; Granit et al. 1963; Nelson and Burke 1967). A relationship between backpropagating spikes and a somatic DAP has also been shown in hippocampus and cortex, although this differs from the mechanism we describe here by incorporating dendritic $\mathrm{Ca}^{2+}$ current or a somatic $I_{\mathrm{NaP}}$ (Golding et al. 1999; Larkum et al. 1999; Magee and Carruth 1999; Mainen and Sejnowski 1996; Wang 1999; Yuste et al. 1994; Zhang et al. 1993). Spike doublets have been reported in bursting cells ranging from receptors to cortical pyramidal cells (Calvin and Hartline 1977; Calvin and Sypert 1976; Granit et al. 1963; Koch 1999; Lo et al. 1998; Nelson and Burke 1967; Paré et al. 1995; Steriade et al. 1993). Spike doublets have been shown to contribute to synchronizing neuronal discharge, but no specific role in burst formation has been identified (Ermentrout and Kopell 1998; Koch 1999; Whittington et al. 1997). The conditional backpropagation described in the present study may then contribute to the generation of burst output in other cell types.

Spike bursts in cortical cells have become recognized for their role in encoding stimulus location, orientation, and spatial frequency selectivity (Gray and McCormick 1996; Lisman 1997). Similarly, burst discharge in ELL pyramidal cells has a direct role in feature extraction in vivo (Gabbiani et al. 1996; Metzner et al. 1998). Pyramidal cell spike bursts in vivo occur with interspike intervals in the range of $8-25 \mathrm{~ms}$ and a lower limit of 4-5 ms (Metzner et al. 1998; J. Bastian, unpublished data). Close examination of published records in Metzner et al. (1998) would indicate that not all pyramidal cell spike bursts in vivo show the progressive increase in intraburst spike frequency we found in vitro. Similarly, unit discharges resembling spike doublets are apparent in in vivo recordings, al- though not all bursts recorded end with a spike doublet. Therefore conditional backpropagation is not necessary to account for all burst discharge of pyramidal cells in vivo. This would be expected for short-lasting depolarizations that do not sufficiently drive pyramidal cells to incorporate the entire process of dendritic spike broadening and conditional backpropagation. Rather, conditional backpropagation likely represents one of several factors controlling burst output during electrosensory processing.

This research was supported by the Canada Medical Research Council and the Alberta Heritage Foundation for Medical Research. N. Lemon was supported by a MRC Studentship, and R. W. Turner is an AHFMR Senior Scholar.

\section{REFERENCES}

Aldrich RW, GetTing PA, AND Thompson SH. Mechanism of frequencydependent broadening of molluscan neuron soma spikes. J Physiol (Lond) 291: 531-544, 1979.

AZOUZ R, JENSEN MS, AND YAARI Y. Ionic basis of spike after-depolarization and burst generation in adult rat hippocampal CA1 pyramidal cells. J Physiol (Lond) 492: 2111-2223, 1996.

BORST JGG AND SAKMANN B. Facilitation of presynaptic calcium currents in the rat brainstem. J Physiol (Lond) 513.1: 149-155, 1999.

BouRque CW. Calcium-dependent spike after-current induces burst firing in magnocellular neurosecretory cells. Neurosci Lett 70: 204-209, 1986.

BouRque CW. Activity-dependent modulation of nerve terminal excitation in a mammalian peptidergic system. Trends Neurosci 14: 28-30, 1991.

Bullock TH and HeILIGENBERG W. Electroreception. New York: John Wiley, 1986.

Buzsáki G, PentTonen M, NÁdasdy Z, and Bragin A. Pattern and inhibitiondependent invasion of pyramidal cell dendrites by fast spikes in the hippocampus in vivo. Proc Natl Acad Sci 93: 9921-9925, 1996.

Callaway JC and Ross WN. Frequency-dependent propagation of sodium action potentials in dendrites of hippocampal CA1 pyramidal neurons. J Neurophysiol 74: 1395-1403, 1995.

CALVIN WH AND HaRTLine DK. Retrograde invasion of Lobster stretch receptor somata in control of firing rate and extra spike patterning. J Neurophysiol 40: $106-118,1977$

CALVin WH AND SyPert GW. Fast and slow pyramidal tract neurons: an intracellular analysis of their contrasting repetitive firing properties in the cat. J Neurophysiol 39: 420-434, 1976.

Chen WR, MidTGaARd J, AND ShePherd GM. Forward and backward propagation of dendritic impulses and their synaptic control in mitral cells. Science 278: 463-467, 1997.

Colbert CM, Magee JC, Hoffman, DA, and Johnston D. Slow recovery from inactivation of $\mathrm{Na}^{+}$channels underlies the activity-dependent attenuation of dendritic action potentials in hippocampal CA1 pyramidal neurons. J Neurosci 17: 6512-6521, 1997.

ERmentrout GB AND Kopell N. Fine structure of neural spiking and synchronization in the presence of conduction delays. Proc Natl Acad Sci USA 95: 1259-1264, 1998.

Gabbiani F, Metzner W, Wessel R, and Koch C. From stimulus encoding to feature extraction in weakly electric fish. Nature 384: 564-567, 1996.

GHAmari-Langroud M AND BouRque CW. Caesium blocks depolarizing after-potentials and phasic firing in rat supraoptic neurones. J Physiol (Lond) 510: $165-175,1998$.

Golding NL, Jung, H-Y, Mickus T, AND SpRuSton N. Dendritic calcium spike initiation and repolarization are controlled by distinct potassium channel subtypes in CA1 pyramidal neurons. J Neurosci 19: 8789-8798, 1999.

Granit R, Kernell D, AND Smith RS. Delayed depolarization and the repetitive response to intracellular stimulation of mammalian motoneurones. J Physiol (Lond) 168: 890-910, 1963.

GRAY CM AND MCCORMICK D. Chattering cells: superficial pyramidal neurons contributing to the generation of synchronous oscillations in the visual cortex. Science 274: 109-113, 1996.

HeIligenberg W. Neural nets in electric fish. Cambridge, MA: MIT Press, 1991.

Higashi H, TANAKE E, INOKUCHI H, AND Nishi S. Ionic mechanisms underlying the depolarizing and hyperpolarizing afterpotentials of single spike in guinea-pig cingulate cortical neurons. Neuroscience 55: 129-138, 1993. 
Hoenn K, Watson TWJ, and MacVicar BA. A novel tetrodotoxin-insensitive, slow sodium current in striatal and hippocampal neurons. Neuron 10: 543-552, 1993.

HugUENARD JR. Low-threshold calcium currents in central nervous system neurons. Аnпи Rev Physiol 58: 329-348, 1996.

JACKSON MB, KonNERTH A, AND Augustine GJ. Action potential broadening and frequency-dependent facilitation of calcium signals in pituitary nerve terminals. Proc Natl Acad Sci USA 88: 380-384, 1991.

Johnston D, Magee JC, Colbert CM, And Christie R. Active properties of neuronal dendrites. Annu Rev Neurosci 19: 165-186, 1996.

Jung HY, MickUs T, AND SPRUSTON N. Prolonged sodium channel inactivation contributes to dendritic action potential attenuation in hippocampal pyramidal neurons. J Neurosci 17: 6639-6646, 1997.

KLEmic KG, ShIeH C-C, KiRsch GE, and Jones SW. Inactivation of Kv2.1 potassium channels. Biophys $J$ 74: 1779-1789, 1998.

Косн C. Biophysics of Computation. New York: Oxford, 1999.

Kotecha S, Eley DW, AND TuRner RW. Tissue printed cells from teleost electrosensory and cerebellar structures. J Comp Neurol 386: 277-292, 1997.

LARKum ME, Kaiser KMM, AND SAKMANn B. Calcium electrogenesis in distal apical dendrites of layer 5 pyramidal cells at a critical frequency of backpropagating action potentials. Proc Natl Acad Sci USA 96: 14600-14604, 1999.

LARKUM ME, Rioult MG, AND LuSCHER H-R. Propagation of action potentials in the dendrites of neurons from rat spinal cord slice cultures. $J$ Neurophysiol 75: 154-170, 1996.

LEMON N, LOWE M, AND TURNER RW. Factors controlling oscillatory discharge in pyramidal cells of the electrosensory lateral line lobe (ELL) of weakly electric fish. Int Congress Neuroethol Abst 1998, p. 27.

LEMON N AND TURNER RW. Backpropagating spikes regulate oscillatory spike bursts. XXIX Proc Soc Neurosci Abst 25(1): 455, 1999.

LISMAN JE. Bursts as a unit of neural information: making unreliable synapses reliable. Trends Neurosci 20: 28-43, 1997.

Lo FS, CoRK RJ, AND Mize RR. Physiological properties of neurons in the optic layer of the rat's superior colliculus. J Neurophysiol 80: 331-343, 1998.

MA M AND KOESTER J. Consequences and mechanisms of spike broadening of R20 cells in Aplysia californica. J Neurosci 15: 6720-6734, 1995.

MAGEE JC AND CARRUTH M. Dendritic voltage-gated ion channels regulate the action potential firing mode in hippocampal CA1 pyramidal neurons. J Neurophysiol 82: 1895-1901, 1999.

MAINEN ZF AND SEJNOWSKI TJ. Influence of dendritic structure on firing pattern in model neocortical neurons. Nature 382: 363-365, 1996.

MALER L. The posterior lateral line lobe of certain gymnotoid fish: quantitative light microscopy. J Comp Neurol 183: 323-363, 1979.

MALER L, SAS E, AND Rogers J. The cytology of the posterior lateral line lobe of high frequency weakly electric fish (Gymnotidae): dendritic differentiation and synaptic specificity in a simple cortex. J Comp Neurol 195: 87-139, 1981.

Massengill JL, SMith MA, Son DI, AND O'Dowd DK. Differential expression of $\mathrm{K}_{4-\mathrm{AP}}$ currents and Kv3.1 potassium channel transcripts in cortical neurons that develop distinct firing phenotypes. J Neurosci 17: 3136-3147, 1997.

Mathes C, Rosenthal JJC, Armstrong CM, AND Gilly WF. Fast inactivation of delayed rectifier $\mathrm{K}$ conductance in squid giant axon and its cell bodies. J Gen Physiol 109: 435-448, 1997.

MathiESON WB AND MALER L. Morphological and electrophysiological properties of a novel in vitro slice preparation; the electrosensory lateral line lobe brain slice. J Comp Physiol 163: 489-506, 1988.

METZNER W AND JuRANeK J. A sensory brain map for each behavior? Proc Natl Acad Sci USA 94: 14798-14803, 1997.

Metzner W, Koch C, Wessel R, and Gabbiani F. Feature extraction of burst-like spike patterns in multiple sensory maps. J Neurosci 15: 2283 2300, 1998.

Mickus T, Jung HY, AND SpRUston N. Properties of slow, cumulative sodium channel inactivation in rat hippocampal CA1 pyramidal neurons. Biophys $J$ 76: 846-860, 1999.

Moller P. Electric Fishes. New York: Chapman and Hall, 1995.
Morales E, Sinclair S, and Turner RW. Somatic and dendritic $\mathrm{K}^{+}$channels in pyramidal cells of the electrosensory lobe (ELL) of the weakly electric fish. Int Congress Neuroethol Abst 1998, p. 27.

NeLSON PG AND BuRKE RE. Delayed depolarization in cat spinal motoneurons. Exp Neurol 17: 16-26, 1967.

PARÉ D, PAPE H-C, AND DONG J. Bursting and oscillating neurons of the basolateral amygdaloid complex in vivo: electrophysiological properties and morphological features. J Neurophysiol 74: 1179-1191, 1995.

Quattrocki EA, Marshall J, and KaCZMareK LK. A Shab potassium channel contributes to action potential broadening in peptidergic neurons. Neuron 12: 73-86, 1994.

RASHID AJ AND DunN RJ. A family of Kv3-related $\mathrm{K}^{+}$channels in the weakly electric fish Apteronotus leptorhynchus. Int Congress Neuroethol Abst 1998a, p. 26.

RASHID AJ AND DunN RJ. Sequence diversity of voltage-gated potassium channels in an electric fish. Mol Brain Res 54: 101-107, 1998b.

Ritz R AND SEJNOwSKI TJ. Synchronous oscillatory activity in sensory systems: new vistas on mechanisms. Curr Opin Neurobiol 7: 536-546, 1997. Rudy B, Chow A, Lau D, Amarillo Y, Ozaita A, Saganich M, Moreno H, Nadal MS, Hernandez-Pineda R, Hernandez-Cruz A, Erisir A, LeONARD C, AND Vega-SAEnZ DE Miera E. Contributions of Kv3 channels to neuronal excitability. Ann NY Acad Sci 868: 304-343, 1999.

Shao LR, Halvorsrud R, Borg-Graham L, and Storm JF. The role of BK-type $\mathrm{Ca}^{2+}$-dependent $\mathrm{K}^{+}$channels in spike broadening during repetitive firing in rat hippocampal pyramidal cells. J Physiol (Lond) 521: 135-146, 1999.

SHumway CA. Multiple electrosensory maps in the medulla of weakly electric gymnotiform fish. I. Physiological differences. J Neurosci 9: 4388-4399, 1989.

Spruston N, Schiller Y, Stuart G, and Sakmann B. Activity-dependent action potential invasion and calcium influx into hippocampal CA1 pyramidal cells. Science 268: 297-300, 1995.

Steriade M, Timofeev I, Durmuller N, and Grenier F. Dynamic properties of corticothalamic and local cortical interneurons generating fast rythmic (30-40 Hz) spike bursts. J Neurophysiol 79: 483-490, 1998.

StUART GJ AND SAKMANN B. Active propagation of somatic action potentials into neocortical pyramidal cell dendrites. Nature 367: 69-72, 1994.

Stuart GJ, Shiller J, AND Sakmann B. Action potential initiation and propagation in rat neocortical pyramidal neurons. J Physiol (Lond) 505: 617-632, 1997.

TSUBOKAWA H AND Ross WN. IPSPs modulate spike backpropagation and associated $\left[\mathrm{Ca}^{2+}\right]_{\mathrm{i}}$ changes in the dendrites of hippocampal CA1 pyramidal neurons. J Neurophysiol 76: 2896-2906, 1996.

TURNER RW, MALER L, AND BurRows M (Editors). Electrolocation and electrocommunication. J Exp Biol 202, 1999.

Turner RW, Maler L, Deerinck T, LeVinson RS, and Ellisman MH. TTX-sensitive dendritic sodium channels underlie oscillatory discharge in a vertebrate sensory neuron. $J$ Neurosci 14: 6453-6471, 1994.

TuRner RW, MEyers DER, Richardson TL, AND BARKER JL. The site for initiation of action potential discharge over the somato-dendritic axis of rat hippocampal CA1 pyramidal neurons. J Neurosci 11: 2270-2280, 1991.

TURNER RW, PlANT J, AND MALER L. Oscillatory and burst discharge across electrosensory topographic maps. J Neurophysiol 76: 2364-2382, 1996.

WANG XJ. Fast burst firing and short-term synaptic plasticity: a model of neocortical chattering neurons. Neuroscience 89: 347-362, 1999.

White G, LOVIngER DM, and WeIGHT F. Transient low-threshold $\mathrm{Ca}^{2+}$ current triggers bursting firing through an afterdepolarization potential in an adult mammalian neuron. Proc Natl Acad Sci USA 86: 6802-6806, 1989.

Whittington M, Stanford I, Colling S, Jefrerys J, and Traub R. Spatiotemporal patterns of gamma frequency oscillations tetanically induced in the rat hippocampal slice. J Physiol (Lond) 328: 621-624, 1997.

Yuste R, Gutnick MJ, SaAR D, Delaney KR, and Tank DW. $\mathrm{Ca}^{2+}$ accumulations in dendrites of neocortical pyramidal neurons: an apical band and evidence for two functional compartments. Neuron 13: 23-43, 1994.

Zhang L, Valiante TA, and CARLEn PL. Contribution of the low-threshold T-type calcium current in generating the post-spike depolarizing afterpotential in dentate granule neurons of immature rats. J Neurophysiol 70: 1-9, 1993. 